\title{
CORRIGENDUM
}

\section{Methodology for studying postprandial lipid metabolism}

\author{
D Lairon, J Lopez-Miranda and C Williams \\ European Journal of Clinical Nutrition (2008) 62, 1154; doi:10.1038/ejcn.2008.42
}

Correction to: European Journal of Clinical Nutrition (2007) 61, 1145-1161; doi:10.1038/sj.ejcn.1602749.

Since the publication of this review, the authors have identified an inadvertent error regarding the attribution of Table 2 'Factors affecting the postprandial triglyceride response to a test meal' to the original source and would like to make immediate amends.

In page 1148 , the following sentence should be the last sentence in the paragraph 2: Table 2 lists the factors that affect post prandial triglyceride response to a test meal summarized earlier (Parks, 2001).

In page 1148, Table 2 and its caption should read as shown below:

The following reference needs to be added to the reference list:

Parks EJ (2001). Recent findings in the study of postprandial lipemia. Curr Atheroscler Rep 3, 462-470.

The authors apologize for any inconvenience or confusion this inadvertent error may have caused.

Table 2 Factors affecting the postprandial response to a test meal (summarized by Parks, 2001)

\begin{tabular}{|c|c|}
\hline Characteristics of the test meal & Effect on triglyceride (TAG) response \\
\hline Increase in fat content of meal & Increases TAG AUC \\
\hline Alcohol consumption before the meal, and with the meal & Increases TAG AUC \\
\hline Polyunsaturated fatty acid composition of meal & Increases postprandial peak TAG \\
\hline Cholesterol addition to meal & Delays time to return to baseline TAG concentration \\
\hline Fiber addition & Generally decreases the TAG response \\
\hline Palatability & Butter increases or decreases the TAG response \\
\hline Ratio of fat to protein and carbohydrate & Addition of glucose to meal increases TAG AUC \\
\hline \multicolumn{2}{|l|}{ Patient characteristics that alter the response } \\
\hline Baseline TAG concentration & Higher fasting concentrations lead to higher postprandial TAG \\
\hline Lipoprotein phenotype & $\begin{array}{l}\text { Phenotypes with higher baseline TAG concentrations are associated with higher } \\
\text { postprandial TAG. CAD patients with apoE2/E3 have significantly increased TAG AUC }\end{array}$ \\
\hline Age of patient & $\begin{array}{l}\text { Older patients have higher TAG concentrations, but could be simply an effect of higher } \\
\text { baseline TAG }\end{array}$ \\
\hline Hydration status & Dehydration causes blood concentrations to be higher \\
\hline Time of last exercise bout & Recent exercise reduces the postprandial response \\
\hline Time of day test is administered & Late-night testing shows delayed return to baseline \\
\hline
\end{tabular}

